fact that half of all students will become GPs and very few specialist ophthalmologists.

The pitiable funding of academic general practice posts means that we are few to become involved in all aspects of specialist training; but most medical schools now have general practice departments more than willing to combine effort. These two articles exemplify just how important such cooperation should be.

MARTIN LAWRENCE

\author{
Department of Community Medicine and \\ General Practice, \\ University of Oxford \\ Oxford OX2 6HE
}

SIR,-Steroid eyedrops, the common panacea for a sore red eye, had a good buffeting. The verdict of both the papers and of the leading article by $\mathrm{Mr} \mathrm{D}$ St Clair Roberts is simply that they should not be prescribed without a check by an ophthalmologist. In an ideal and affluent world, maybe; but when the delay for an outpatient visit may be months or years.... Oh, dear.

We are well aware that steroid drops can worsen a dendritic keratitis, which the questionnaire to ophthalmologists of Dr C M P Claoué and Ms Katherine E Stevenson predictably confirmed; but they did reassuringly find that, while three of their correspondents reckoned that "this problem was .. becoming more common," 93 (the overwhelming majority) thought it was now less common. Is there such cause for alarm? Their message was then reiterated by Messrs Michael J Lavin and Geoffrey E Rose, who found that out of 1800 Moorfields casualty patients 54 had received steroids, of whom three (all with keratitis) suffered further visual loss. They noted that each of these three had presented with "impaired vision." So it would have been tempting to deduce that steroids were a safe treatment for sore red eyes as long as the vision was unimpaired. Incidentally no cases of steroid induced glaucoma were recorded.

The trouble is that steroid drops are often far the most effective dampers down of an allergic blepharoconjunctivitis, probably the commonest cause of itchy red eyes. We should indeed be reminded of the risks and be chary of using these drops whenever the vision is impaired, in unilateral cases (dendritic ulcers are normally unilateral, while blepharitis is bilateral), in the elderly (blepharitis mainly troubles the young, who are far less prone to glaucoma), and for long periods (the episodic discomfort of blepharitis usually yields fairly promptly - and the drops should, of course, be tailed off as soon as symptoms clear, or if they do not help). But with these reservations there are surely occasions when general practitioners can properly prescribe weak steroid drops rather than hold back for a distant outpatient appointment, by which time the signs may have gone and the symptoms just linger as an unhappy memory.

PATrick TREVOR-Roper

London NW1 4JL

\section{Gastrointestinal investigation of iron deficiency anaemia}

SIR,-We share the anxiety of Dr Ian J Cook and colleagues (24 May, p 1380) that patients with iron deficiency anaemia in whom a benign upper gastrointestinal lesion is found at endoscopy may be harbouring more serious colonic disease.

None the less, the finding of seven such patients in their study group of 100 may not be as important as at first sight. Rectal bleeding was a symptom in three of these and since overt gastrointestinal haemorrhage was a criterion for exclusion from their study this should be investigated in its own right. Furthermore, four of the patients had adenomatous polyps, and these are known to be a common finding in the general population. In a recent necropsy study from Liverpool colonic adenomas were found in $40 \%$ of patients over 65 years, although most were less than $1 \mathrm{~cm}$.' However, we would agree that full colonic investigation is important in the elderly, particularly when the upper gastrointestinal lesion is of questionable importance. We would not, for example, accept hiatus hernia alone as a cause for iron deficiency anaemia without concomitant erosive oesophagitis

We have recently examined the role of upper gastrointestinal endoscopy in 342 patients with iron deficiency anaemia who had no history of blood loss. There was a similar high diagnostic yield, with an overall finding of an ulcerative lesion capable of producing chronic blood loss in $59 \%$ of our patients. The prevalence of disease increased greatly with age, from $37 \%$ in patients aged under 40 years to $70 \%$ in those aged over 70 years; contrary to the findings of Dr Cook and others, chronic duodenal ulceration was quite common (29 patients, 23 of whom were over 60 years). An upper gastrointestinal carcinoma was found in 37 otherwise asymptomatic patients but none were aged under 65. A final important finding was the discovery of unsuspected coeliac disease in five patients. Two of them were premenopausa women, one of whom had previously had a hysterectomy for recurrent anaemia; this finding highlights the value of duodenal biopsies in the young person referred for upper gastrointestinal endoscopy as part of the investigation of iron deficiency anaemia.

M V TOBIN

Gastroenterology Unit,

Royal Liverpool Hospital

Liverpool L7 8XP

1 Williams AR, Balasooriva BAW, Day DW. Polyps and cancer of the large bowel: a necropsy study in Liverpool. Gut 1982;23 $835-42$

SIR,-The Lesson of the Week by Dr I J Cook and colleagues (24 May, p 1380) is an important one. I have seen several patients with iron deficiency anaemia that has been attributed to upper gastrointestinal lesions who later proved to have colonic neoplasms

The most recent was a 76 year old woman found to have iron deficiency anaemia (haemoglobin $77 \mathrm{~g} / \mathrm{l}$, mean corpuscular volume $67 \mathrm{fl}$, serum iron $<5$ $\mu \mathrm{mol} / \mathrm{l}$, total iron binding capacity $65 \mu \mathrm{mol} / \mathrm{l}$ ) during an admission before a hip replacement. She had been taking piroxicam for two years and had recurren epigastric discomfort. Tests for faecal occult blood were strongly positive. Sigmoidoscopy showed nothing abnormal, but upper gastrointestinal endoscopy showed a small inferior duodenal ulcer with contact bleeding. She was treated with ranitidine and ferrous sulphate. Despite this she became anaemic on two further occasions during the next year, requiring blood transfusion and oral iron. On both occasions the anaemia was attributed to the duodenal ulcer, and no further investigations were performed.

Fifteen months after the initial presentation she was admitted to our unit with anaemia and melaena. Haemoglobin was $73 \mathrm{~g} / \mathrm{l}$. A right sided abdominal mass was palpable and barium enema showed a carcinoma of the ascending colon with almost complete obstruction of the lumen. A right hemicolectomy was performed and the tumour was a moderately differentiated adenocarcinoma (Dukes's stage B) There had been no recurrence of anaemia when she was seen six months later, and tests for faecal occult blood were negative.

In retrospect, it seemed obvious that her recurren anaemia should not have been attributed to the small duodenal ulcer, but two years before this a single contrast barium enema (performed for investigation of right iliac fossa pain and occasional loose stools) showed sigmoid diverticulae only, and this almost certainly misled her medical attendants.

I agree with the authors' conclusion that a benign lesion found on upper gastrointestinal endoscopy does not exclude the need for colonic investigation in patients with microcytic iron deficiency anaemia, and this does not apply only to elderly patients. A similar conclusion was reached in a Lesson of the Week five years ago which reported on a 56 year old woman and a 68 year old man with occult large bowel carcinomas whose anaemia was initially attributed to gastritis and duodenal ulcer respectively. ${ }^{1}$ It is surprising that this was not referred to, particularly as one of the authors appears to be the same.

S FREESTONE

University Department of Clinical Pharmacology,

Royal Infirmary,

Edinburgh EH3 9 YW

1 Riley JW, Wilson PC, Grant AK. Double pathology as a cause of occult gastrointestinal blood loss. Br Med f 1981;282:626-7.

\section{Pseudo-obstruction}

SIR,-I was interested to read the leading article by Professor H A F Dudley and Dr S Paterson-Brown ( 3 May, p 1157). One of the common causes of pseudo-obstruction that we see is the result of sensitivity to, or overdose of, psychotropic or bronchodilator drugs.

The triptylines are notorious for their sympathomimetic effects of inhibiting gut motility, and these may affect predominantly the colon Difficulty in emptying the bladder may be an associated problem. Salbutamol (Ventolin), a $\beta_{2}$ sympathetic agonist, may have an inhibitory effect on colonic motility, with gross distension of the colon and abdomen as secondary effects. The patient may have increasing difficulty in breathing as a consequence and take even more salbutamol by inhalation, compounding the problem.

Withdrawal of these drugs and a slow intravenous infusion (over 40 minutes) of $20 \mathrm{mg}$ of phentolamine or guanethidine will usually trigger the restoration of gut motility. This treatment is also effective in reflexly initiated ileus. Blood pressure should be monitored and the patient kept in bed, the drip being slowed if necessary. The treatment is essentially one of taking off the brakes on normal gut motility. Colonoscopy and caecal exteriorisation should not be considered until sympatholytic therapy has been tried. Early caecal or colonic tenderness is not a contraindication to such a trial.

B N CATChPOLE

Department of Surgery

The Queen Elizabeth II Medical Centre,

Nedlands, Western Australio 6009

Australia

\section{High altitude haemofiltration}

SIR,-I agree with Dr P E Stevens and his colleagues (24 May, p 1354) that in patients with acute renal failure continuous arteriovenous haemofiltration permits control of their fluid problems. However, I note that during transfer the haemoglobin remained constant in the first patient and in the second it dropped by $17 \mathrm{~g} / \mathrm{l}$. This occurred in spite of the fact that both patients had been ultrafiltrated by two litres, which was confirmed by a rise in urea concentration and a drop in central venous pressure.

I wonder whether during treatment the haemofilter clotted as a result of sparing heparinisation ( $500 \mathrm{U} / \mathrm{h})$. This unexplained blood loss occurred during haemofiltration, a treatment which not only 